\title{
Potato extract inhibits lipase activity and ameliorates gut microbiome dysbiosis and weight gain in mice fed a high-fat diet
}

\author{
Dorsilla Anono Katimbwa', Jinsung Ma ${ }^{1}$, Chang-Kil Kim², Dongyup Hahn ${ }^{1}$ and Jinkyu Lim ${ }^{1 *}$ (D)
}

\begin{abstract}
Curtailing the absorption of triglycerides (TGS) is a preferred pathway for treating obesity. Our previous study demonstrated that the water-soluble fraction from potato could inhibit the lipase activity of patatin, one of the major proteins in potato. This aqueous fraction was purified and concentrated by deproteination and reversed-phase chromatography to investigate the effectiveness against obesity. Biochemical analyses indicated that the fraction non-competitively inhibited pancreatic lipase (PLase) with a half-maximal inhibitory concentration of $10.17 \mu \mathrm{g} / \mathrm{mL}$, and was named as potato-derived lipase inhibitory fraction (PI). Animal studies on C57BL/6 mice showed that in mice fed a high-fat diet (HFD), PI treatment resulted in reductions in body weight gain, adipose fat deposition, and liver TGs, and ameliorated the gut microbiome dysbiosis caused by HFD feeding; meanwhile, orlistat, a well-known lipase inhibitor, diverged the gut microbiome profile in mice fed a HFD. High resolution electronspray ionization-Orbitrap tandem mass spectrometry identified gallic acid, 4-hydroxybenzoic acid, and protocatechuic acid, which are known to have lipase inhibitory activities, in PI. However, these compounds could not reconstitute comparable specific inhibitory activity of PI inferring the existence of another inhibitory compound(s) to be identified in PI.
\end{abstract}

Keywords: Gut microbiome, Obesity, Pancreatic lipase inhibition, Potatoes (Solanum tuberosum L. tubers)

\section{Introduction}

According to the World Health Organization, the prevalence of obesity tripled from 1975 to 2016, with 1.9 billion adults and an estimated 41 million children less than 6 years old classified as either overweight or obese [1]. Obesity has been associated with an increased risk of disability and early mortality and an increased incidence of morbidities, such as cardiovascular disease, diabetes, cancer, non-alcoholic fatty liver disease [2], and gut microbiome dysbiosis, such as alterations in relative abundances of different bacterial phyla, specifically $\mathrm{Bac}$ teroidetes and Firmicutes [3, 4].

\footnotetext{
*Correspondence: jkylim@knu.ac.kr

1 Department of Food Biomaterials, Kyungpook National University, 80

Daehak-Ro, Buk-Gu, Daegu, Korea

Full list of author information is available at the end of the article
}

The primary driver of obesity is an energy imbalance caused by excessive calorie consumption, frequently through the consumption of calorie-dense, high-fat foods, combined with low-calorie expenditures. This phenomenon is exacerbated by the modern sedentary lifestyle, and, as such, the mitigation of fat absorption by inhibiting pancreatic lipase (PLase) is a principal research goal in the field of obesity treatment $[5,6]$.

Many different compounds and extracts from plant and microbial sources have been investigated and reported in the search for PLase inhibitors [7-9]. Among the identified natural substances with PLase inhibition activities, orlistat, a hydrogenated form of lipstatin originally isolated from Streptomyces toxytricini is one of the best-selling drugs under the trade name of Xenical (Roche, Basel, Switzerland) for the treatment of diet-induced obesity [10]. The success of orlistat has spawned research into identifying other enzyme inhibitors from natural sources 
with fewer unpleasant or ameliorated side effects of orlistat, such as oily stools, flatulence, fecal urgency, and abdominal cramps [11].

Potatoes (Solanum tuberosum L.) contain approximately $5 \%$ protein $-40 \%$ of which is from the patatin protein family [12]. Patatin primarily serves as a storage protein and is also a lipid acyl hydrolase that could lysis lipid and inhibit larval growth [13]. Our previous comparative analysis of the lipid acyl hydrolase activity of patatin in 14 different cultivars of potatoes suggested that lipase inhibition activities in potatoes among which the Sumi cultivar was chosen as the ideal candidate for evaluation of lipase inhibitor activity in potatoes. In the current study, we isolated and purified the lipase-inhibiting fraction from potato to characterize its mechanism of action and to assess its lipase inhibitory capacity in vitro with different fatty acid esters and triglycerides (TGs), as well as in vivo using obesity-induced C57BL/6 mice. Its amelioration effects on the dysbiosis of the gut microbiome in mice fed a high-fat diet (HFD) were also assessed. Furthermore, ion-exchange chromatography (IEC) and high-resolution tandem mass spectrometric analysis (MS/MS) were used to evaluate the active components within PI.

\section{Materials and methods}

\section{Preparation of $\mathrm{PI}$ and identification of active components}

The potatoes were peeled and shredded in a blender with distilled water at a ratio of $500 \mathrm{~mL} / \mathrm{kg}$ potatoes to derive a slurry. The slurry was stirred using a magnetic stirrer for $1 \mathrm{~h}$ at room temperature (RT). The extract was filtered through cheesecloth and then centrifuged at $10,000 \times g$ for $20 \mathrm{~min}$ to remove the insoluble matter. The proteins were precipitated by adding 4 volumes of acetone and kept overnight at $4{ }^{\circ} \mathrm{C}$. The sample was then centrifuged at $10,000 \times g$ for $20 \mathrm{~min}$ at $4{ }^{\circ} \mathrm{C}$ to pellet the precipitated proteins and polysaccharides. The supernatant was then decanted and vacuum-dried at $36{ }^{\circ} \mathrm{C}$ to evaporate the acetone. The remaining aqueous fraction was frozen in freeze-drying bottles and lyophilized in a vacuum freeze dryer. The lyophilized powder was retrieved and dissolved in a minimum amount of deionized water (approximately $1 \mathrm{~mL} / \mathrm{mg}$ of powder) and stored at $-80{ }^{\circ} \mathrm{C}$ until use.

Concentrated hydrochloric acid was added to the reconstituted potato extract to lower its $\mathrm{pH}$ to 3.0 to precipitate patatin $[14,15]$ and maintained at $4{ }^{\circ} \mathrm{C}$ for $2 \mathrm{~h}$. The mixture was then centrifuged at $10,000 \times g$ for $20 \mathrm{~min}$ at $4{ }^{\circ} \mathrm{C}$ to pellet the precipitated patatin and specific polysaccharides.

The supernatant was serially extracted with equal volumes of dichloromethane, ethyl acetate, and butanol with vigorous mixing and phase separation. After phase separation, the dichloromethane, ethyl acetate, butanol, and the final aqueous fractions were vacuum-dried at $36{ }^{\circ} \mathrm{C}$ until the solvent was completely evaporated. Then, $1.0 \mathrm{~g}$ of the combined vacuum-dried extract from the butanol and ethyl acetate layers was dissolved in $100 \mathrm{~mL}$ of deionized water, and added to a glass column prepacked with $100 \mathrm{~g}$ of $\mathrm{C} 18$ resin (RS Tech, Chungcheongbuk-do, South Korea), equilibrated with deionized water. Upon loading the sample and collecting the flowthrough, the column was washed with $600 \mathrm{~mL}$ of deionized water, then eluted with a stepwise gradient starting from $100 \mathrm{~mL}$ of $10 \%$ methanol up to $100 \%$ methanol with an increment of $10 \%$ at each step. The flow-through and washed fractions, which contained most of the PLase inhibitory activity, were then lyophilized, dissolved in a minimum amount of deionized water (approximately $1 \mathrm{~mL} / 600 \mathrm{mg}$ of the residue), designated as potatoderived lipase inhibitory fraction, PI, and kept frozen at $-80{ }^{\circ} \mathrm{C}$.

\section{Biochemical assays for lipase inhibition p-Nitrophenylbutyrate substrate}

The inhibitory effect of PI on pancreatic lipase was assessed based on a previous method with slight alterations using $p$-nitrophenylbutyrate ( $p$-NPB) (SigmaAldrich, St. Louis, MO, USA) as a substrate [16] by measuring the absorbance at $410 \mathrm{~nm}$ using a Sunrise microplate reader (Tecan Group AG, Mannerdorf, Switzerland). PLase, procured from Sigma-Aldrich (St. Louis, MO, USA), was freshly prepared and pre-warmed at $37{ }^{\circ} \mathrm{C}$ for $10 \mathrm{~min}$ before each assay by dissolving it in $100 \mathrm{mM}$ of sodium phosphate buffer ( $\mathrm{pH}$ 7.4) to make a PLase suspension with a final concentration of $15 \mathrm{mg} /$ $\mathrm{mL}$. Then, $10 \mu \mathrm{L}$ of various concentrations of sample (dissolved in deionized water) were mixed with $40 \mu \mathrm{L}$ of $0.1 \mathrm{M}$ sodium phosphate buffer (pH 7.4), $10 \mu \mathrm{L}$ of $20 \mathrm{mM}$ $p$-NPB (dissolved in absolute ethanol) and deionized water for a final volume of $180 \mu \mathrm{L} /$ well. For the inhibitory control, $10 \mu \mathrm{L}$ of orlistat $(1 \mathrm{mg} / \mathrm{mL}$ in DMSO) was used. Next, $10 \mu \mathrm{L}$ of the PLase suspension was added into the assay mixture and the reaction plate was then incubated at $37^{\circ} \mathrm{C}$ for $20 \mathrm{~min}$, and absorbance was measured as previously described. This experiment was conducted in duplicate.

\section{4-Methylumbelliferyl oleate substrate}

PLase inhibition by PI using a fluorescent substrate, 4-methylumbelliferyl oleate (4-MUO), was assessed [17]. The assay was set up in triplicate in an opaque 96-well plate; 4-MUO was dissolved in a $13 \mathrm{mM}$ Tris buffer, $150 \mathrm{mM}$ sodium chloride and $1.3 \mathrm{mM}$ calcium chloride solution to make a $0.5 \mathrm{mM}$ suspension. Each well contained $40 \mu \mathrm{L}$ of $0.05 \mathrm{M}$ Tris buffer ( $\mathrm{pH} 8$ ), $10 \mu \mathrm{L}$ of 
PI and $10 \mu \mathrm{L}$ of the prepared 4-MUO suspension, mixed with $10 \mu \mathrm{L}$ of pre-warmed PLase suspension $(15 \mathrm{mg} / \mathrm{mL})$. Deionized water was then added for a total volume of $100 \mu \mathrm{L}$. Orlistat ( $1 \mathrm{mg} / \mathrm{mL}$ in DMSO) was again used as an inhibitory control. The assay mixture was incubated at $37{ }^{\circ} \mathrm{C}$ for $20 \mathrm{~min}$ and then stopped by adding $100 \mu \mathrm{L}$ of $0.1 \mathrm{M}$ sodium citrate ( $\mathrm{pH}$ 4). Fluorescence was measured on an Infinite F200 PRO fluorescence microplate reader (Tecan Group AG, Mannerdorf, Switzerland) at an excitation wavelength of $360 \mathrm{~nm}$ and an emission wavelength of $460 \mathrm{~nm}$. The specific lipase inhibition was calculated by dividing the difference between total and residual lipase activity with the total activity (negative control) for $10 \mu \mathrm{L}$ of the sample $[18,19]$.

\section{Triglyceride substrate}

The commercial Lipoprotein Lipase (LPLase) Activity Assay Kit (Cell Biolab Inc., San Diego, CA, USA) was adopted to analyze the inhibition of pancreatic lipase by PI using a fluorogenic triglyceride analog as the substrate. TG hydrolase activity was assayed in accordance with the manufacturer's instructions. Both LPLase and PLase were assayed against the inhibitor, PI, at stepped volumes of 1,5 and $10 \mu \mathrm{L}$ of $200 \mu \mathrm{g} / \mathrm{mL}$ to assess inhibition. As a positive control, $10 \mu \mathrm{L}$ of orlistat $(1 \mathrm{mg} / \mathrm{mL}$ of DMSO) was also used.

\section{Kinetics, dose-response and storage stability analysis}

The inhibition kinetics of PI was assessed at concentrations of $0.99,3.98$, and $15.94 \mu \mathrm{g} / \mathrm{mL}$, which were each mixed with 4-MUO at concentrations of $0.447,0.669,1$, $1.5,2.27$, and $3.4 \mathrm{mM}$. Orlistat was also used for comparison at concentrations of $0.00048,0.0024$, and $0.012 \mu \mathrm{g} /$ $\mathrm{mL}$. Furthermore, $40 \mu \mathrm{L}$ of $0.05 \mathrm{M}$ Tris buffer ( $\mathrm{pH} 7.4$ ), $10 \mu \mathrm{L}$ of PLase $(15 \mathrm{mg} / \mathrm{mL})$, and deionized water were added to each well to bring the total reaction volume to $100 \mu \mathrm{L}$. The plate was incubated at $37{ }^{\circ} \mathrm{C}$ with shaking at $60 \mathrm{rpm}$. Readings were taken every $2 \mathrm{~min}$ for fluorescence at $360 \mathrm{~nm}$ excitation and $460 \mathrm{~nm}$ emission a total of 10 times. The inhibition mechanism was analyzed by Lineweaver-Burk double reciprocal plotting of the enzyme reaction velocity $(1 / \mathrm{V})$ against substrate concentrations $(1 / \mathrm{S})[20]$.

Dose-response analysis of PI took place at the final concentration of $0.025,0.1,0.4,1.56,6.25,25$, and $100 \mu \mathrm{g} / \mathrm{mL}$. Orlistat was also used at the same concentrations as a positive control. The inhibitor concentrations were prepared and tested for percentage inhibition using 4-MUO as a substrate, as described above. The resultant values were then converted to \%-inhibition and plotted against the inhibitor concentration. After plotting the data, the resultant dose's logarithmic function versus the
PLase activity (\%) curve was obtained from least-squares regression to calculate the $\mathrm{IC}_{50}$.

\section{Determination of PI composition}

Anion-IEC was used for further purification of PI before MS/MS analysis; $95.3 \mathrm{mg} / \mathrm{mL}$ of PI dissolved in $5 \mathrm{mM}$ ammonium acetate was added to the DEAE-Sepharose column (Sigma-Aldrich., St. Louis, MO, USA) equilibrated using the same buffer. The column was then stepwise eluted using $3 \mathrm{~mL}$ of the following solvents; $0.01 \mathrm{M}$, $0.01 \mathrm{M}, 0.1 \mathrm{M}$, and $1 \mathrm{M}$ formic acid. The eluents were collected separately, neutralized, and assayed for lipase inhibitory activity using 4-MUO as a substrate. The active fraction from the anion-IEC was concentrated and analyzed using a Q-Exactive quadrupole Orbitrap tandem mass spectrometer with negative $(-)$ electrospray ionization (ESI). Then, $0.15 \mathrm{mg} / \mathrm{mL}$ of the active eluent dissolved in methanol/water $(70: 30 \mathrm{v} / \mathrm{v})$ was used for the MS/MS analysis. The sample flow rate into the ionizer was $10 \mu \mathrm{L} / \mathrm{min}$. The Orbitrap MS/MS was set as follows: mass resolution power (FWHM) 140,000 at $\mathrm{m} / z 200$, spray voltage of $4.50 \mathrm{kV}$, capillary temperature of $300{ }^{\circ} \mathrm{C}$, S-lens $\mathrm{R}_{\mathrm{f}}$ level of $50 \mathrm{~V}$, mass range of $m / z 100-1000$, and collisional energy of $10-30 \mathrm{eV}$.

A spectral interpretation was performed using software with an automated peak-picking algorithm. The calibrated peaks with $\mathrm{S} / \mathrm{N}>6$ were extracted and assigned to chemical formulas (mass error within $1.5 \mathrm{ppm}$ ) using said software [21].

The compounds identified by MS/MS were cross-referenced with published works and analyzed for lipase inhibitory activity using 4-MUO as a substrate. Analysis of the relative abundance of the compounds singled out by published works was carried out by HPLC using a reversed-phase $(\mathrm{C} 18)$ column Acclaim $^{\mathrm{TM}}$ Polar Advantage II-4.6 $\times 250 \mathrm{~mm}$, particle size, $5 \mu \mathrm{m}$, Thermo Scientific, San Jose, CA, USA). The column temperature was maintained at $25{ }^{\circ} \mathrm{C}$. The mobile phase consisted of $10 \%$ methanol, $90 \%$ water and $0.1 \%$ trifluoroacetic acid, infused at a flow rate of $1 \mathrm{~mL} / \mathrm{min}$. The sample, in an injection volume of $10 \mu \mathrm{L}$, was separated in the isocratic mode using a UV detector at a wavelength of $274 \mathrm{~nm}$. The eluted peaks were collected, lyophilized and assayed for lipase inhibitory activity.

\section{Animals and diet}

The experiments were performed in compliance with the guidelines of the Ethics and Animal Welfare of Kyungpook National University and were approved by the Institutional Review Board (KNU-2019-0034-1). A total of 40 5-week-old male C57BL/6 mice were obtained from Orient-Bio Inc. (Seongnam-si, Gyeonggi-do, Korea). Research diets were procured from Research Diet (New 
Brunswick, NJ, USA). The mice had ad libitum access to water and chow during the first week of acclimatization. They were maintained under controlled conditions of $23 \pm 1{ }^{\circ} \mathrm{C}$ and light-dark periods of $12 \mathrm{~h}$. They were then split into four groups of 10 each: normal diet (ND) (D12450J, 10\% kcal from fat), high-fat diet (HFD) (D12492, 60\% kcal from fat), HFD with orlistat, and HFD with PI. Orlistat-treated mice received $200 \mathrm{mg}$ of orlistat per $\mathrm{kg}$ of diet, while those treated with PI received $5 \mathrm{~g}$ of PI per liter of drinking water based on the $\mathrm{IC}_{50}$ ratio of the two treatments, i.e., 1:21 (Orlistat/PI). PI was added to the drinking water because it is hygroscopic and rendered the diets too soft to supplement in this fashion. The treatment period was 8 weeks, after which clinical tests were performed. The mice were then euthanized by cervical dislocation or $\mathrm{CO}_{2}$ exposure, followed by organ and blood sample collection. Fecal samples were collected weekly for each group.

\section{Glucose and insulin tolerance tests}

At the end of the 8-week treatment period, biochemical assays were conducted on all animals before euthanasia. A fasting glucose measurement was taken after a 6 h daytime fast, followed by an intraperitoneal (IP) glucose tolerance test (IPGTT) via an IP injection of glucose of $1.5 \mathrm{~g} / \mathrm{kg}$ body weight, and an IP insulin tolerance test (IPITT) via an IP injection of insulin of $1 \mathrm{U} / \mathrm{kg}$ body weight. Blood glucose was measured using an SD Glucometer (SD Biosensor Inc., Suwon, Gyeonggi-do, Korea) on blood collected from the tip of the tail vein.

\section{Body weight, organ and abdominal fat measurements}

The mice were weighed once per week until sacrifice. Organs, including the liver and cecum, and epididymal and perirenal fat were dissected from the mice after sacrifice, weighed, and stored promptly in sterile snap cap tubes at $-80^{\circ} \mathrm{C}$ until further processing and analysis.

\section{Serum biochemistry and liver and fecal TG analysis}

Blood biochemistry and C-reactive protein levels were analyzed at the Laboratory Animal Center of the DaeguGyeongbuk Medical Innovation Foundation (Daegu, Korea). Interleukin-6 (IL-6) in the blood was analyzed by an ELISA kit by following the manufacturer's instructions (Komabiotech, Seoul, Korea). TGs in the liver tissues and fecal samples were extracted by adding $800 \mu \mathrm{L}$ of HPLC-grade acetone to $150-350 \mathrm{mg}$ of the sample [22] In brief, samples were lysed until full homogenization. The homogenized sample-acetone mixtures were then incubated with agitation at RT overnight. The mixture was then centrifuged at $10,000 \times g$ for $10 \mathrm{~min}$ at RT and the supernatant was removed and dried in a speed vacuum. The lipid extract was kept in aliquots $(50 \mu \mathrm{L})$ and stored at $-80{ }^{\circ} \mathrm{C}$. Hepatic and fecal TG determinations were completed using a TG-S assay kit purchased from Asan Pharm. Co. (Suwon, Gyeonggi-do, Korea) by following the manufacturer's instructions. The TG content was standardized to concentration $(\mathrm{mg} / \mathrm{dL})$ per milligram of liver tissue or fecal sample.

\section{Microbiome analysis by $16 \mathrm{~S}$ sequencing}

The cecal contents of 3 mice from each group $(n=10)$ were thawed and extracted to assess genomic DNA therein using a QiAamp DNA Stool Mini Kit (Qiagen, Stockach, Germany). The sequencing of the bacterial 16S rDNA V3-V4 region was performed on an Illumina MiSeq platform by Chunlab Inc. (Seoul, Korea), followed by pipeline analysis for $16 \mathrm{~S}$-based microbial profiling. After quality filtration and merger of the raw data, the operational taxonomic units (OTUs) were clustered according to the methods devised by Rideout et al. [23] and annotated against an in-house EZBioCloud $16 \mathrm{~S}$ rRNA database by the USEARCH program, with a $\geq 97 \%$ similarity cut-off after normalizing the gene copy number and the number of reads to a maximum of 41,170 reads. The raw data was then visualised and analysed for alphadiversity (Shannon and Simpson indexes), beta-diversity and principal component analysis (PCA) via the interactive web services provided by ChunLab [24].

\section{Preparation of cecal extracts for gas chromatography- mass spectrometry (GC-MS)}

Approximately $0.1 \mathrm{~g}$ of frozen cecal content was placed in a $20 \mathrm{~mL}$ glass vial and dissolved in $10 \mathrm{~mL}$ of water. The sample was maintained at $70{ }^{\circ} \mathrm{C}$ for $10 \mathrm{~min}$. Then, a Solid Phase MicroExtraction 50/30 $\mu \mathrm{m}$ fiber assembly with a divinylbenzene/carboxen/polydimethylsiloxane coating (Supelco, Bellefonte, PA, USA) was plugged in and the sample was incubated at $70{ }^{\circ} \mathrm{C}$ for $30 \mathrm{~min}$ to allow the absorption of volatile short-chain fatty acids (SCFAs) [25]. After incubation, the fiber was removed and placed in a $\mathrm{GC}-\mathrm{MS}$ auto-sampler.

\section{SCFA analysis by GC-MS}

Total SCFA content was quantitatively analyzed by gas chromatography on an Agilent 7890 (Palo Alto, CA, USA) with a DB-FFAP chromatographic capillary column $(30 \mathrm{~m} \times 250 \mu \mathrm{m} \times 0.25 \mu \mathrm{m}$; Agilent $)$ under the following conditions: Initial temperature of $50{ }^{\circ} \mathrm{C}$ for $1 \mathrm{~min}$, heating to $240{ }^{\circ} \mathrm{C}$ at a rate of $10{ }^{\circ} \mathrm{C} / \mathrm{min}$, followed by maintenance at $240{ }^{\circ} \mathrm{C}$ for $30 \mathrm{~min}$. The signal was then detected at $250{ }^{\circ} \mathrm{C}$ with a $70 \mathrm{eV}$ ionization voltage using an Agilent 5975C mass selective detector (MSD) system. Acetic, propionic, and butyric acids were used as standards, and serial dilutions were plotted to generate a calibration curve of response to the concentration $(\mu \mathrm{M})$. 
The resultant values were standardized to $\mu \mathrm{M}$ per gram of cecal content based on the sample's initially recorded mass.

\section{Statistical analysis}

In vitro and in vivo data are presented as mean \pm standard error of the mean (SEM). Statistical analysis was done using SPSS statistics 22 software (SPSS Inc., Chicago, IL, USA). Data from the analyses were assessed for significant differences using one-way analysis of variance (ANOVA) and Duncan's multiple range test. The statistical difference between ND and HFD-fed groups was determined by Student t-test. $p<0.05$ was considered statistically significant.

\section{Results and discussion}

\section{PI characteristics and lipase inhibition}

The supernatant from the deproteination step was serially extracted using dichloromethane, ethyl acetate, and butanol. Ethyl acetate, butanol, and water phases showed the relative lipase inhibitory activities of 24.4, 18.9, and $56.7 \%$, respectively, while the dichloromethane phase had no inhibitory activity (Table 1 ). Although water had the highest retention of lipase inhibitory components, as evidenced by its yield and lipase inhibition values, a substantial amount of the lipase inhibitory activity was extracted in butanol and ethyl acetate. These results suggest that the lipase inhibitory component contains polar functional groups enabling water solubility and hydrophobic moieties allowing solubility in non-polar solvents.

For further purification, the butanol- and ethyl acetate-phase extracts were preferable due to lower salt and protein concentrations than the water-phase extract. Extracts from the butanol and ethyl acetate phases were mixed and applied to a pre-packed C18 column

Table 1 Lipase inhibitory activities in the extracts of different solvent phases

\begin{tabular}{llll}
\hline Extraction & $\begin{array}{l}\text { Volume } \\
\text { of reconstituted } \\
\text { extract }(\mathrm{mL})\end{array}$ & $\begin{array}{l}\text { Specific } \\
\text { inhibitory } \\
\text { activity }^{\mathbf{a}}\end{array}$ & $\begin{array}{l}\text { Relative } \\
\text { inhibitory } \\
\text { activity (\%) }\end{array}$ \\
\hline Dichloromethane & 15 & n.d. $^{\mathrm{c}}$ & 0 \\
Ethyl acetate & 15 & $0.58 \pm 0.017$ & $24.4 \pm 1.28$ \\
Butanol & 15 & $0.45 \pm 0.018$ & $18.9 \pm 1.00$ \\
Water & 35 & $0.58 \pm 0.001$ & $56.7 \pm 2.46$ \\
\hline
\end{tabular}

a The specific lipase inhibition was calculated by dividing the difference between the total and the residual lipase activity with the total lipase activity (negative control) for $10 \mu \mathrm{L}$ of the sample. 4-Methylumbelliferyl oleate (4-MUO) was used as a substrate. Orlistat (positive control) revealed $100 \%$ inhibition at a concentration of $0.01 \mathrm{mg} / \mathrm{mL}$

b The relative inhibitory activity was calculated as a fraction of the inhibitory activity from the total activity in all different solvent phases

c Not detected equilibrated with deionized water, and then eluted with a stepwise increasing concentration of methanol. The assay for lipase inhibition using 4-MUO as a substrate and PLase as a target enzyme showed that most of the lipase inhibitory activity was found in the flow-through and wash fractions with 88 and $70 \%$ of recovery yields, respectively (Table 2); subsequent methanol eluents showed little activity (Additional file 1: Fig. S1). The flow-through fraction was freeze-dried, reconstituted in deionized water, and then designated as potato-derived lipase inhibitory fraction, PI.

The storage stability of PI was tested at various temperatures over a period of 4 weeks. The results (Additional file 1: Fig. S2) showed that the lipase inhibitory activity of PI persisted at high efficiency for 4 weeks at temperatures ranging from 4 to $37^{\circ} \mathrm{C}$.

To compare the lipase inhibition efficiency of PI according to the length of fatty acid chain, substrates with $p$-nitrophenyl as a chromophore ester-bonded to octanoate (C8), decanoate (C10), myristate (C14), or palmitate (C16) were incubated with PLase in the presence or absence of PI for $30 \mathrm{~min}, 1 \mathrm{~h}$, and $24 \mathrm{~h}$. Regardless of the chain length of the substrate, PI showed efficient lipase inhibitory ability for all of the tested substrates, and this inhibitory ability last even after $24 \mathrm{~h}$ of incubation (Additional file 1: Fig. S3).

To see if the inhibition efficiency of PI for PLase is applied to other types of lipases, such as, bacterial lipase, inhibition assays were performed by incubating bacterial lipase or PLase with changing concentrations of PI using triolein as a substrate. The results from the lipase inhibition assay indicated that PI and orlistat inhibited triglyceride breakdown by bacterial lipase and porcine PLase in a dose-dependent manner (Fig. 1b) with higher activities in PLase.

Lineweaver-Burk double reciprocal plotting was performed to determine the mechanism of inhibition of

Table 2 Lipase inhibitory activities of the C18 column fractions

\begin{tabular}{lllc}
\hline Fraction & $\begin{array}{l}\text { Volume } \\
\text { of reconstituted } \\
\text { extract }(\mathbf{m L})\end{array}$ & $\begin{array}{l}\text { Specific } \\
\text { inhibitory } \\
\text { activity }^{\mathbf{a}}\end{array}$ & Yield (\%) $^{\mathbf{b}}$ \\
\hline Concentrated extract & 100 & 0.50 & 100 \\
C18 flow-through & 50 & 0.88 & 88 \\
C18 wash & 50 & 0.70 & 70
\end{tabular}

a The specific lipase inhibition was calculated by dividing the difference between the total and the residual lipase activity with the total lipase activity (negative control) for $10 \mu \mathrm{L}$ of the sample. 4-MUO was used as a fluorescent substrate. Orlistat revealed $100 \%$ inhibition (positive control) at a concentration of $0.01 \mathrm{mg} / \mathrm{mL}$

b The yield was calculated as a relative inhibitory activity in each fraction compared by the total activity in the "concentrated extract" 


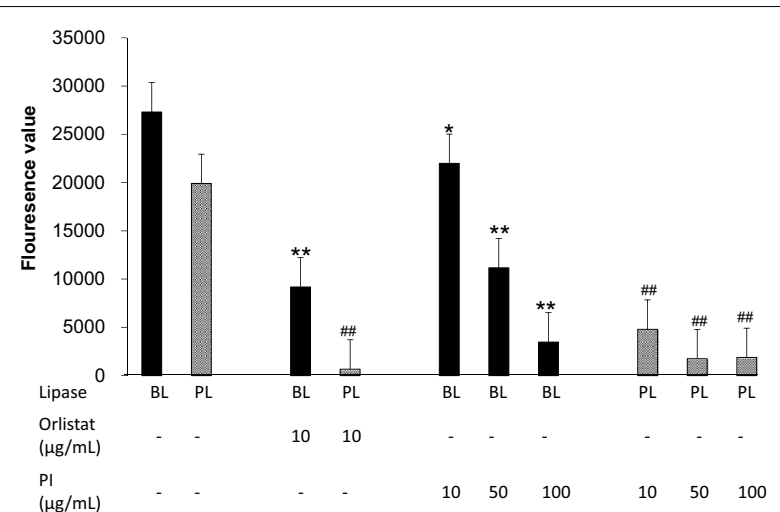

Fig. 1 The inhibitory activity of PI on triglyceride (TG) hydrolysis by bacterial lipase (BL, black bar) and pancreatic lipase (PL, grey bar) is represented by fluorescence emitted by triolein (excitation wavelength of $485 \mathrm{~nm}$ and emission wavelength of $525 \mathrm{~nm}$ ). Data represented in mean $\pm S D$. Significant differences between the positive controls (lipase activity without inhibitor) and the inhibitor treatments (orlistat or PI) are designated with * $(p<0.05)$ or ** and \#\# $(p<0.01)$

lipase activity by PI. Plots with the same $\mathrm{x}$-intercept (unaffected $\mathrm{K}_{\mathrm{m}}$ ), but different slopes and y-intercepts (varied $\mathrm{V}_{\max }$ ) suggest that PI is a non-competitive inhibitor (Fig. 2a), indicating that the hydrophilic and watersoluble active component(s) in PI could bind to the substrate or enzyme-substrate complex allosterically, thereby, preventing binding to the substrate. In contrast, orlistat inhibition occurs when it binds competitively [26] to the active site on the lipase enzyme.

The potency of the inhibitory activity of PI was analyzed using 4-MUO lipase substrate. The resultant fluorescence data was first converted into \%-inhibition and then plotted against the inhibitor concentration. The estimated $\mathrm{IC}_{50}$ of PI was $10.17 \mu \mathrm{g} / \mathrm{mL}$ (Fig. 2b), compared to $0.48 \mu \mathrm{g} / \mathrm{mL}$ for orlistat (Fig. 2c). From the comparison of the $\mathrm{IC}_{50}$ values of PI and orlistat, we can predict that PI has lower potency toward pancreatic lipase than orlistat does, but still has high specific activity among other inhibitors for pancreatic lipase isolated from plants [27].

\section{PI supplementation effects on the mice fed a HFD}

During the 8-week experimental period, PI-supplementation in the mice fed a HFD was shown to reduce weight gain at a comparable rate to orlistat-treated group (Fig. 3a). PI-treatment was associated with lower final body weights, at an average of $29.8 \pm 2.5 \mathrm{~g}$ compared to $38.24 \pm 3.5 \mathrm{~g}$ of the control HFD group. This result was similar to orlistat-treatment, associated with a final average weight of $28.4 \pm 2.5 \mathrm{~g}$. The reduction in body weight gain in the PI-treatment group was despite a similar trend in food intake as the HFD group (Additional file 1:

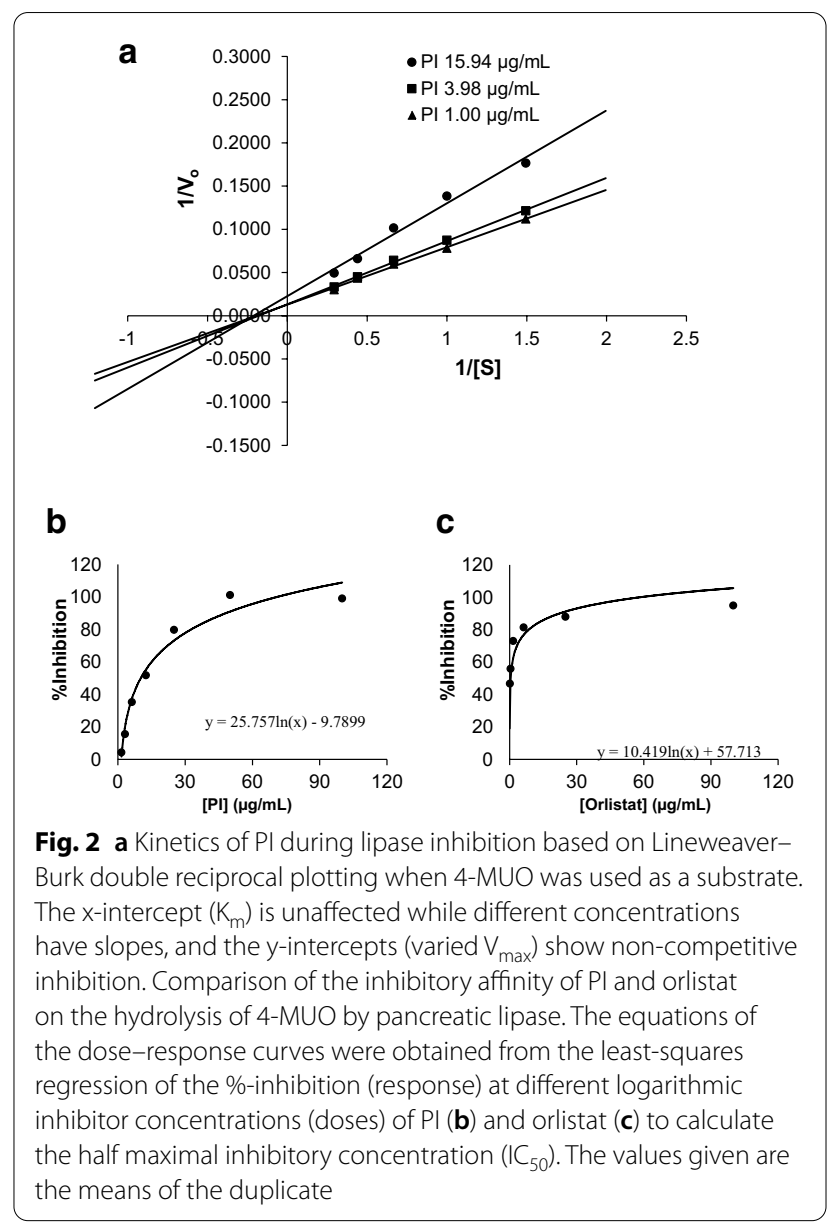

Fig. S4A). However, the inhibitory mechanisms of PI and orlistat in TG digestion is different. PI inhibits lipase activity non-competitively (Fig. 2a) in the small intestine and can be metabolized in the large intestine while orlistat inhibits pancreatic lipase and microbial lipase competitively and stays undegraded in the small and large intestines. Thus, the fecal TG contents of the HFD and HFDPI mice are similar throughout the feeding period, while the HFDOrl group showed increased fecal TG content (Additional file 1: Fig. S4B). PI-treatment reduced perirenal fat in the mice fed a HFD at levels similar to those for the mice treated with orlistat or fed an ND. Similarly, the PI-treated mice showed a reduction in epididymal fat compared to the mice fed a HFD, but did not reach the level of the orlistat-treated mice, who showed lowered epididymal fat than the mice fed an ND (Fig. 3b). The PI-treated mice presented with significantly less TG stored in the liver as compared to the mice fed a HFD $(p=0.003)$. The liver TG accumulation in the PI-treated mice was lowered to that of the mice fed an ND, and this ability was lower than that of the liver TG accumulation by the orlistat-treated mice (Fig. 3c). These findings 


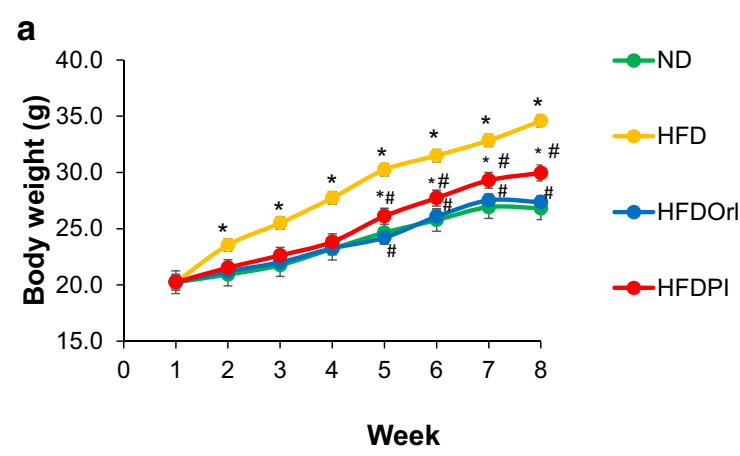

b

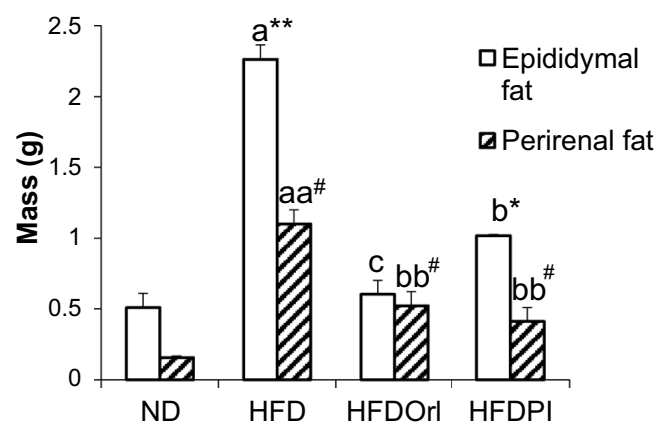

c

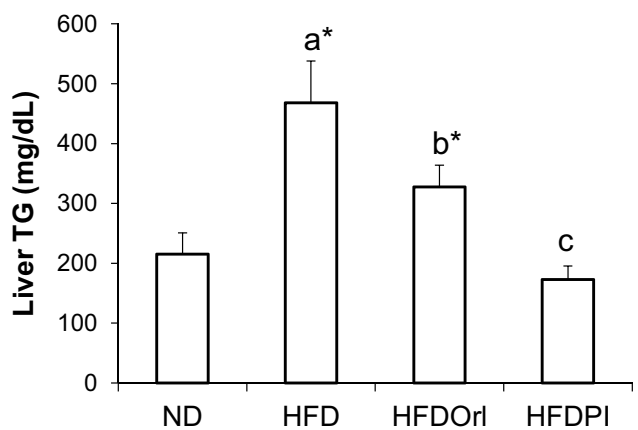

Fig. $3 \mathrm{Pl}$ supplementation affected the body weight and composition of the mice. a The trend of the weight gain (for 8 weeks) in mice on different diets and treatments. All groups had significantly different trends $\left({ }^{*} p<0.05\right)$ except for between the normal diet (ND)-fed and orlistat-treated groups (HFDOrl) $(p=1.000)$. The different trends between HFD and HFDOrl or PI-treated HFD group (HFDPI) are denoted by \# $(p<0.05)$. $\mathbf{b}$ The average mass of epididymal and perirenal fat excised from the four groups. c Concentration of TG per $100 \mathrm{mg}$ of liver tissue from the four groups. Data represented in mean \pm SD. Mean values of HFD, HFDOrl, and HFDPI statistically significant from ND $(p<0.05)$ denoted by *. Different letters above the bars represent significant differences among HFD, HFDOrl, and HFDPI $(p<0.05)$. HFD high fat diet

suggest the lipase inhibitory activity of PI reduces the digestion of TGs in the intestine and truncates increased amount of stored TGs in the liver as a result of intake of a fatty diet in obese individuals [28].

\section{PI improved glucose homeostasis}

To investigate the effect of the supplementation of a HFD with PI on glucose metabolism in obese mice, we analyzed blood glucose levels after administering glucose in a fasted state or injecting insulin.

The fasting blood glucose level in the mice fed a HFD was significantly higher than that of the mice fed an ND (at time 0 of Fig. 4a). The elevated fasting blood glucose level in the mice fed a HFD was reduced to the level of the mice fed an ND by PI and orlistat treatments. Moreover, from IPGTT, both PI and orlistat treatment promoted glucose homeostasis (Fig. 4a) and reduced glucose intolerance, as evidenced by the reduction in the peak blood glucose and area under the curve (AUC) of glucose concentration, seen in the HFD group, to levels comparable to the ND group (Fig. 4a, c). Insulin sensitivity was improved, as well as blood glucose concentrations (AUC) modulated in the PI-treated HFD-fed mice, during the IPITT, to levels observed in the mice fed an ND and to similar levels as the orlistat-treated HFD-fed mice (Fig. 4b, d). These results indicate that PI treatment better improves glucose homeostasis compared to an untreated HFD.

\section{Changes in serum biochemical indicators by $\mathrm{PI}$ treatment}

Dietary supplementation of PI to the mice fed a HFD, although markedly lowered the levels of the serum lipid biochemical markers, did not significantly impact the serum levels of TGs, total cholesterol, high-density lipoprotein (HDL), and low-density lipoprotein (LDL) due to the fluctuations among individuals per group, while significantly lower levels were detected in the ND and orlistat-HFD groups (Table 3). Fluctuations in blood TG levels within groups also precluded the assessment of differences among all four mice groups, which may have been erroneous due to the sample size (Table 3). 

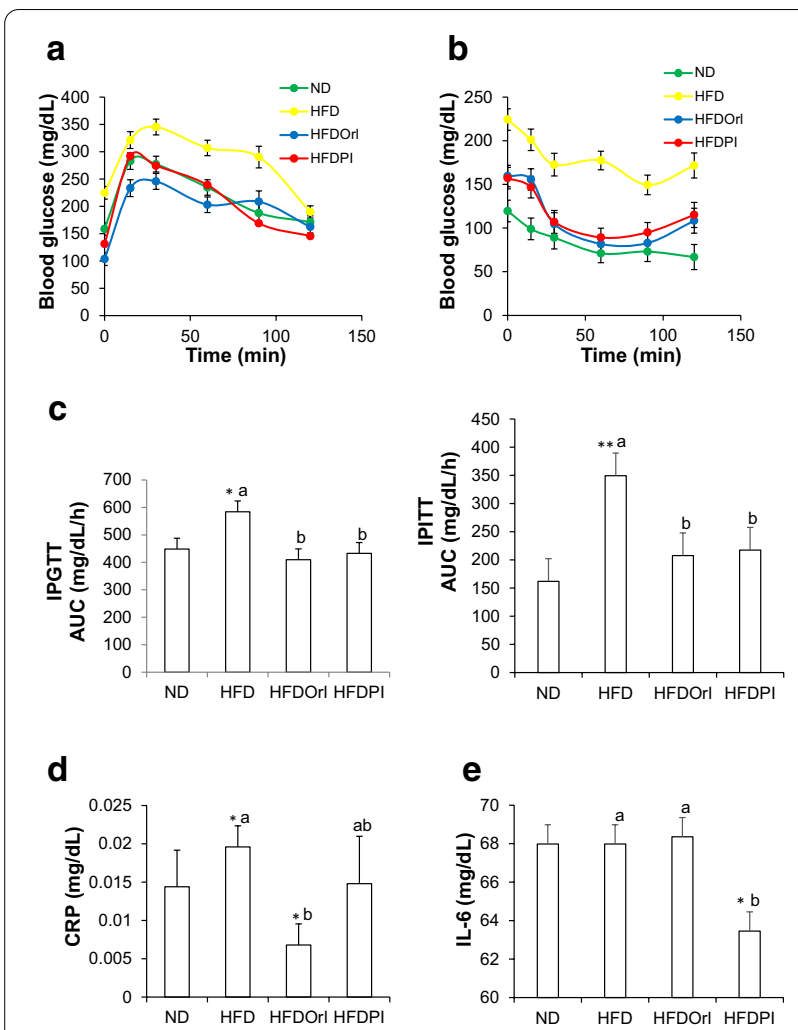

Fig. 4 Serum biochemical values are affected by PI treatment. a ND and PI treatment had significantly similar trends in glucose concentration over time during the intraperitoneal glucose tolerance test (IPGTT), while the orlistat-treated group maintained the lowest blood glucose concentration in comparison to those fed a HFD during the first $60 \mathrm{~min}(p=0.001)$. Meanwhile, the HFD group had the highest blood glucose concentration through-out the test period $(p<0.05)$. b The ND, orlistat, and PI-treated groups all had significantly lower concentrations of blood glucose during the intraperitoneal insulin tolerance test (IPITT) as compared to the HFD group $(p<0.05)$. The area under the curve (AUC) during the IPGTT (c) and the IPITT (d). $\mathbf{e}$ The average concentration of the blood C-reactive protein (CRP) of the four groups. $\mathbf{f}$ The average concentration of the blood interleukin (IL)- 6 in the four groups. Mean values of HFD, HFDOrl, and HFDPI statistically significant from ND $(p<0.05)$ denoted by *. Different letters denote the significance in the differences among HFD, HFDOrl, and HFDPI $(p<0.05)$

It has been known that plasma levels of C-reactive protein (CRP) and IL-6 are highly associated with the progress of obesity. Increased pro-inflammatory cytokine production by $\mathrm{T}$ cells and macrophages is associated with an increased risk of diabetes, hypertension, and cardiovascular disease [29]. CRP, an important marker for vascular inflammation, and IL-6, which has intrinsic pro-inflammatory activity and significantly correlates to excess visceral adiposity, were measured as proxies for inflammation, and a reduction in their levels suggests reduced insulin resistance normally associated
Table 3 Serum lipid profile in the groups after treatment period

\begin{tabular}{llllc}
\hline & $\begin{array}{l}\text { Total } \\
\text { cholesterol } \\
(\mathbf{m g} / \mathbf{d L})\end{array}$ & HDL $(\mathbf{m g} / \mathbf{d L})$ & LDL $(\mathbf{m g} / \mathbf{d L})$ & TG (mg/dL) \\
\hline ND & $113 \pm 8.4$ & $97 \pm 8.4$ & $21.7 \pm 1.7$ & $20 \pm 4.2$ \\
HFD & $174 \pm 14.5^{* \mathrm{~b}}$ & $149 \pm 10.6^{* \mathrm{~b}}$ & $38.2 \pm 5.6^{* \mathrm{~b}}$ & $25.6 \pm 3.0^{* \mathrm{a}}$ \\
HFDOrl & $142 \pm 8.4^{* \mathrm{a}}$ & $119 \pm 7^{* \mathrm{a}}$ & $24.1 \pm 2.5^{\mathrm{a}}$ & $17.6 \pm 3.7^{\mathrm{b}}$ \\
HFDPI & $167 \pm 11.2^{* \mathrm{ab}}$ & $141 \pm 7.5^{* \mathrm{ab}}$ & $33.6 \pm 4.3^{* \mathrm{~b}}$ & $24.8 \pm 6.7^{* \mathrm{a}}$ \\
\hline
\end{tabular}

Data represented as average concentration \pm standard error of the mean (SEM). Mean values of HFD, HFDOrl, and HFDPI statistically significant from $\mathrm{ND}(p<0.05)$ denoted by *. Different letters denote the significance of the differences compared among HFD, HFDOrl and HFDPI $(p<0.05)$

$H D L$ high-density lipoprotein, $L D L$ low-density lipoprotein, $T G$ triacylglycerol

with HFD-induced obesity [30, 31]. In this study, plasma CRP level is higher in the HFD group than in the ND group as expected. However, the plasma CRP level is significantly lower in HFDOrl than in the ND group (Fig. 4d), although the perirenal fat and liver TGs are higher in HFDOrl than in ND (Fig. 3b, c). As the body weight gaining of the HFDOrl mice in 3-month period is comparable to that of the ND mice (Fig. 3a), the decreased level of CRP in the HFDOrl mice can be explained from considering the reports, which showed that elevation of plasma CRP level is highly associated with body-mass index (BMI) [32, 33]. The prolonged supplementation of orlistat to HFD from the beginning of the feeding with HFD for 8 weeks might be another responsible factor for the lowered CRP level.

The plasma level of IL-6 in the HFDPI group is lower compared to those of the groups of ND, HFD, and HFDPI, among which the IL-6 levels are not significantly different (Fig. 4e). The highest caecal SCFA level in the HFDPI mice among other groups (Table 4) can be associated with the lowered IL- 6 because SCFA suppress inflammatory signaling in intestinal cells $[34,35]$.

Table 4 Concentration of short chain fatty acids (SCFAs) in cecal content ( $\mu \mathrm{M} / \mathrm{g}$ of cecal content)

\begin{tabular}{lllll}
\hline Acetic acid & Propionic acid & Butyric acid & $\begin{array}{l}\text { Average } \\
\text { of whole cecal } \\
\text { content (g) }\end{array}$ \\
\hline ND & $56.6 \pm 4.8$ & $57.2 \pm 4.0$ & $17.2 \pm 2.9$ & $0.089 \pm 0.01$ \\
HFD & $54.3 \pm 5.2^{b}$ & $24.1 \pm 2.6^{* b}$ & $19.2 \pm 3.1^{\mathrm{b}}$ & $0.246 \pm 0.03^{* * \mathrm{~b}}$ \\
HFDOrl & $16.6 \pm 3.5^{* \mathrm{c}}$ & $15.4 \pm 1.2^{* \mathrm{c}}$ & $11.3 \pm 2.1^{* \mathrm{c}}$ & $0.382 \pm 0.03^{* * a}$ \\
HFDPI & $94.1 \pm 6.4^{* * a}$ & $58.2 \pm 3.6^{\mathrm{a}}$ & $58.5 \pm 4.1^{* \mathrm{*a}}$ & $0.148 \pm 0.01^{* * \mathrm{c}}$ \\
\hline
\end{tabular}

Data represented as mean concentration $\pm \mathrm{SEM}$. Mean values of HFD, HFDOrl, and HFDPI statistically significant from ND denoted by * $(p<0.05)$ and $* *$ $(p<0.01)$. Different letters denote the significance in the differences among HFD, HFDOrl, and HFDPI $(p<0.05)$ 
(See figure on next page.)

Fig. 5 Effect of PI treatment in a HFD (HFDPI) on diversity index; a Shannon diversity of microbial diversity as compared to mice fed an ND, HFD, and HFD with orlistat treatment (HFDOrlistat). Relative bacterial abundance at the phylum level in response to the PI treatment in a HFD. $\mathbf{b}$ Effects of PI supplementation of a HFD on the relative ratio of Firmicutes to Bacteriodetes (F/B). c The relative abundance of phyla representing less than $1 \%$ of the total bacterial abundance were assembled into "Others". $\mathbf{d}$ Effects on the relative abundance of Proteobacteria, Lachnospiraceae, Ruminococcaceae, Clostridium, and Enterobacteriaceae taxa in the gut as in mice fed an ND, HFD, HFD-Orlistat, and HFD-PI. Mean values of HFD, HFDOrl, and HFDPI statistically significant from ND $(p<0.05)$ denoted by *. Different letters denote the significance in the differences among HFD, HFDOrl, and HFDPI $(p<0.05)$

Liver toxicity was assessed by a histology staining. $\mathrm{H} \& \mathrm{E}$ staining of the liver tissues indicated that the lipid droplets were significantly observed in the HFD group (Additional file 1: Fig. S5). In contrast to the HFD group, no significant macrovesicular steatosis was observed in other groups.

\section{PI attenuated gut microbiota dysbiosis}

To assess the impact of PI in high fat diet fed mice on gut microbiota at the end of 8-week feeding and treatment period, analysis of 16S RNA sequencing using next generation sequencing (NGS) technology was performed in cecal samples from 3 mice from each group obtained immediately after sacrifice.

$\alpha$-Diversity, as assessed by the Shannon index (Fig. 5a), did not vary significantly among the mice fed an ND, HFD, or HFD-PI, but was significantly lower in the HFDorlistat group $(p=0.05)$. For the Chao1 index of species richness index (Additional file 1: Fig. S6A), the ND group had the highest value, followed by the PI-treated and HFD groups; the orlistat-treated group had the lowest value. This same trend was upheld in the number of species observed for each group (Additional file 1: Fig. S6B). Low $\alpha$-diversity is related to reduced feed efficiency [36] which could explain, at least in part, the reduced body weight gain in the orlistat-treated group. The PI-treated group showed similarity to the ND group in $\alpha$-diversity, indicating a reduction from the levels observed in the HFD group. However, this reduction was not statistically significant as in the orlistat-treated group.

The microbiota, as relative phyla abundances, for the individuals $(n=3)$ in the four groups are represented in Fig. 5c. The present data show that the cecal microbiota of the mice were dominated by Bacteroidetes, Firmicutes, and Proteobacteria with other minor phyla (Deferribacteres, Cyanobacteria, Tenericutes, and Verrucornicrobia, among others). Although it is not statistically significant due to the data fluctuation, the HFD group was found to have a higher Firmicutes to Bacteriodetes (F/B) ratio $(0.92 \pm 0.37)$ than the ND group $(0.82 \pm 0.22)$. The treatment with PI in the mice fed a HFD $(0.89 \pm 0.06)$ was associated with reduced F/B ratios similar to those of the mice fed an ND (Fig. 5b). Although orlistat treatment in the mice fed a HFD was also associated with a decreased
F/B ratio, the orlistat microbiome profile diverged from that of the mice fed an ND, most significantly, the relative abundance of Proteobacteria in orlistat group was $48.97 \pm 2.5 \%$ which was highest among the four cohorts (Fig. 5d). An increased abundance of Proteobacteria has been correlated with inflammatory bowel disease, potentially because of changes in transit time [37]. A previous murine model study found a link between gut microbial dysbiosis and obesity development [38], characterized by an increase in Enterobacteriaceae, particularly in the $\gamma$-Proteobacteria class. This increase has been associated with the gut inflammation that accompanies a dramatic reduction in Bacteriodetes abundance and an increase in Firmicutes abundance [39]. Contrary to this, our results indicated that the PI treatment directly reduced the F/B ratio in the mice of a HFD. This would align with the current scientific consensus that many foods and dietary components can affect gut microbiota compositions.

PI treatment was also associated with higher relative abundances of Lachnospiraceae and Ruminococcaceae taxa compared to orlistat treatment in the mice fed a HFD (Fig. 5d). Ruminococcaceae is a member of the phylum Firmicutes in Clostridia cluster XIVa and was higher in the PI-treated mice than in the orlistat-treated mice. The Ruminococcaceae family also contains several butyric acid-producing bacteria with anti-inflammatory properties [40]. Our results also showed increases in other taxa members associated with the orlistat treatment but not PI treatment, including Clostridia and Enterobacteriaceae (Fig. 5d). Proteobacteria's significant increase in the orlistat-treated mice fed a HFD suggests gut microbiota dysbiosis, as this phylum is overrepresented in obese children [41]. These findings, combined with observed higher abundances of Clostridia and Enterobacteriaceae and with PCA of microbial profiles (Fig. 6) in orlistat versus PI, indicate that while the competitive inhibitor of please, orlistat, does reduce the amount of TGs absorbed from the diet, it also contributes to gut dysbiosis [42].

Among the adverse effects of orlistat, such as oily stools, urgent defecation, diarrhea, and abdominal pain [43], diarrhea and abdominal pain might be related to the cecal predominance of Proteobacteria and Enterobacteriaceae (Fig. 5d) and consequently reduced diversity in microbiota and F/B ratio (Fig. 5b, c) [44, 45]. The gut 
a

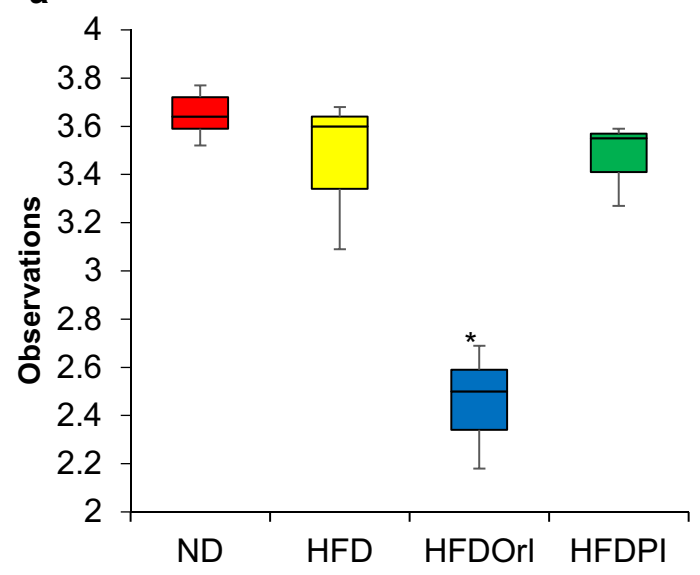

b

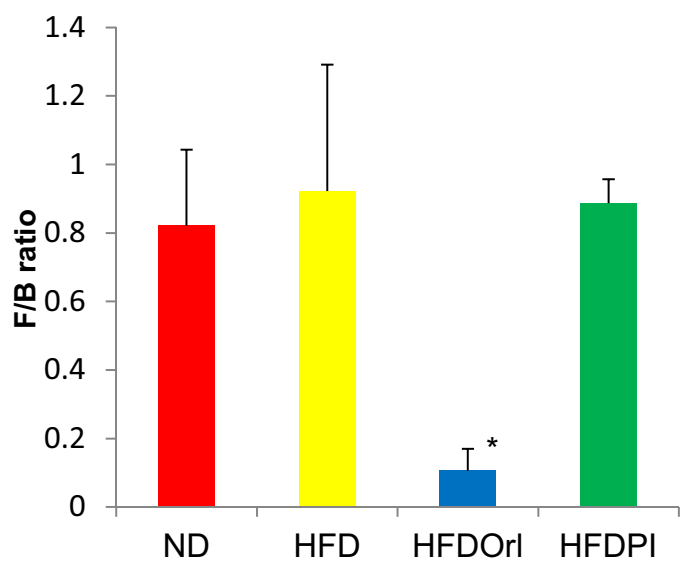

C
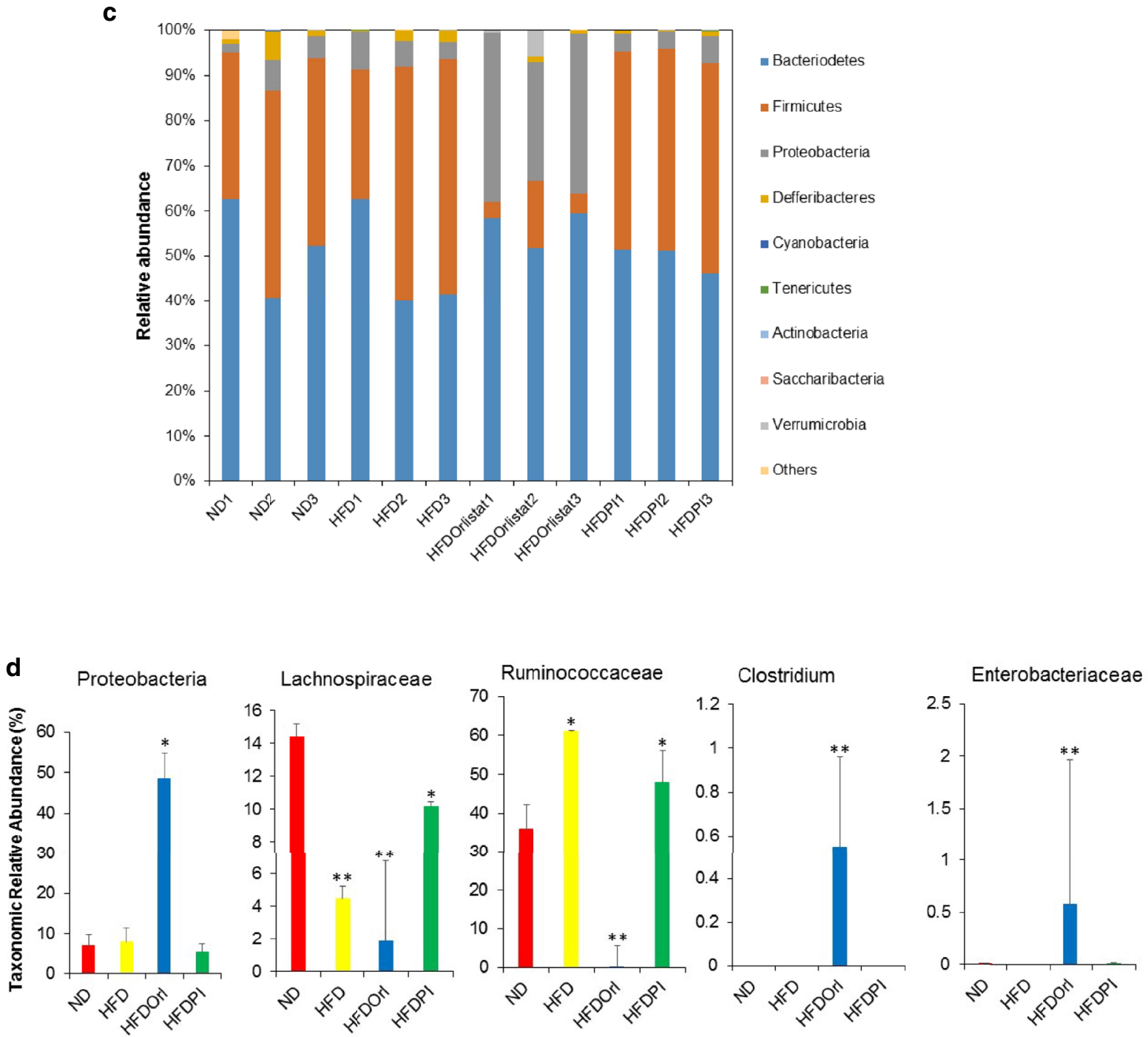


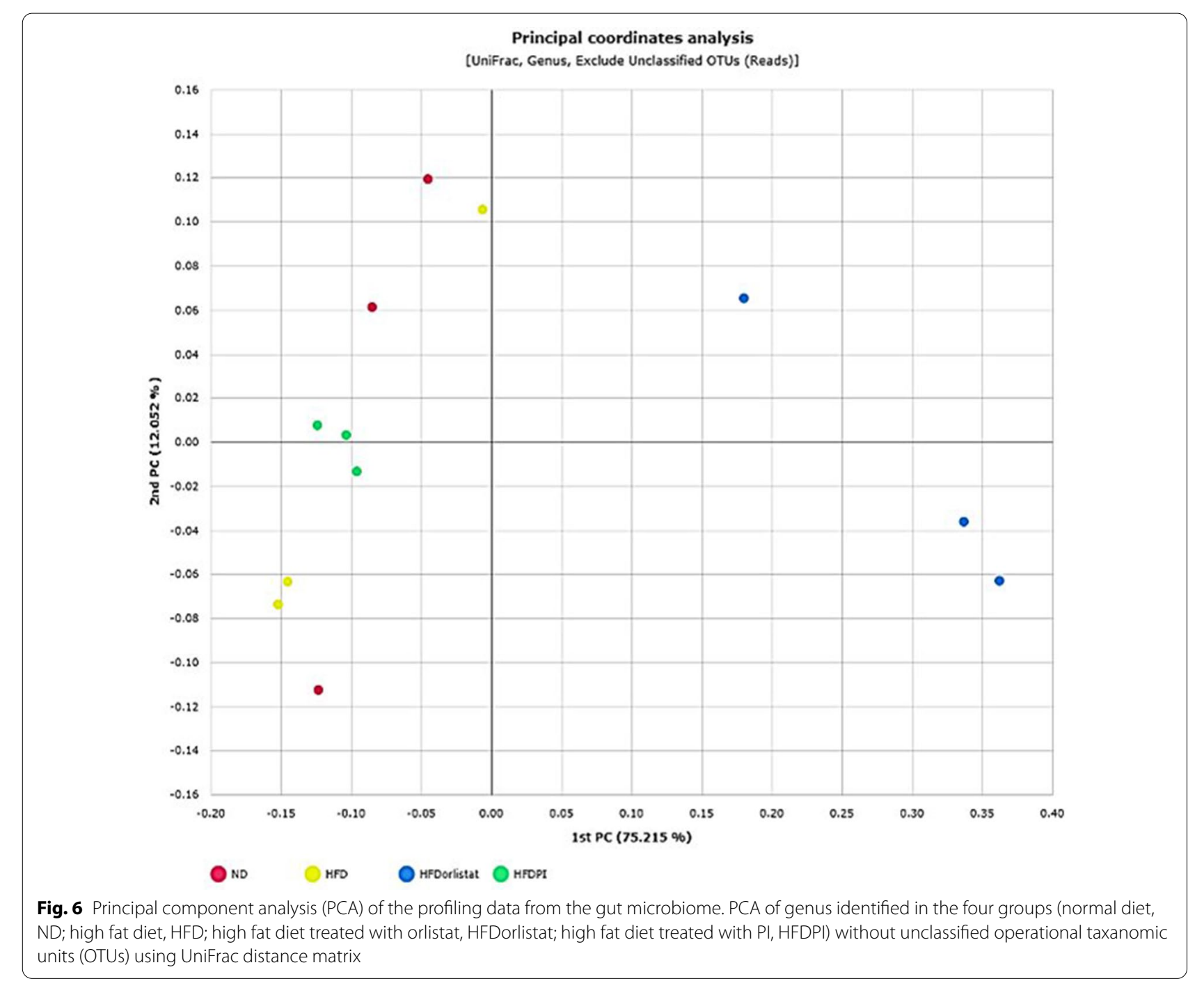

microbiota dysbiosis exerted by an-absorbed TGs by the competitive lipase inhibitor, orlistat, could be improved by water soluble lipase inhibitor, PI, which can be metabolized in the gut and improve the diversity and restore F/B ratio to the level of ND (Fig. 5a-c).

No significant changes in lactic acid-producing bacteria such as Bifidobacterium, Lactobacillus, and Lactococcus were observed following treatment with PI or orlistat, nor were changes observed in other human gut taxa that are known to be beneficial to human health [38, 39], such as Provotella, Feacalibacterium, Bacteroides, and Akkermensia (Additional file 1: Fig. S7).

The microbial profiles of the four groups were then analyzed for $\beta$-diversity, as measured by PCA of genera without unclassified OTUs, using the UniFrac distance matrix (Fig. 6). The results indicate that PI treatment in the mice fed a HFD increased their microbial profile's similarity to that of the mice fed an ND. In alignment with previous results, the orlistat-treated mice presented with a completely different profile from all the other groups; it occupied a different quadrant from them, indicating increased gut microbiome disruption specific and potentially directly linked to the orlistat treatment.

Inhibition of PLase activity by orlistat resulted in an increased concentration of fat retained in the gut, as seen in the significantly larger size of cecal content. This may be the stimuli for the significant change in the microbial profile. In contrast, PI that was shown to contain hydrophilic compounds that the gut microbiota can metabolize, resulting in a gut microbiome profile that was more similar to that of the mice fed an ND. The use of lipase inhibitors that can be degraded by microbiota may therefore provide a pathway for reducing the microbial alterations caused by unabsorbed TGs in the large intestine. 


\section{PI increases colon microbial production of SCFAs}

SCFAs are end products of the colonic microbial fermentation of dietary metabolites [46]. Acetic acid, butyric acid, and propionic acid are common SCFAs produced by commensal gut microbiota to reduce the $\mathrm{pH}$ of the intestinal environment, thereby facilitating the proper structure of intestinal flora, influencing the growth and differentiation of colonocytes, and helping prevent colon cancer $[47,48]$. Therefore, we analyzed the cecal contents of in the mice from each group $(n=4)$ to assess concentrations therein. The PI treatment increased all three SCFAs compared to the orlistat treatment and no treatment HFD groups. The SCFA contents in the ceca of HFD-PI group were comparable or higher than those in the ND group. The acetic acid content was the highest $(94.10 \pm 8.71 \mu \mathrm{M}$ per gram of cecal content) among groups; the propionic acid content was comparable to the ND group $(58.18 \pm 12.0 \mu \mathrm{M}$ per $\mathrm{g}$ of cecal content); the butyric acid content was the highest $(58.25 \pm 17.4 \mu \mathrm{M}$ per $\mathrm{g}$ of cecal content) among groups (Table 4). The amounts of acetic acid and butyric acid in the ceca of the HFD-PI group were higher than those in the ND group, suggesting an enhanced barrier function of the intestinal epithelia [49] and reduced inflammation indicated by reduced IL-6 in the blood (Fig. 4e).

Approximately $90 \%$ of the propionate produced in the colon enters the liver and decreases the lipid content by altering liver metabolic processes [50]. Therefore, the observed dramatic decrease in TGs in the liver of the PI-treated mice fed a HFD could be explained, at least in part, by significantly higher amounts of propionic acid being produced by gut microbiota.

The metabolism of PI in the intestine may also have been responsible for the increased SCFA content in the ceca by directly altering the microbial profile as a prebiotic or acting as a substrate for SCFA production [51].

The results of this study indicate that PI treatment can alleviate obesity and its associated health consequences in mice fed a HFD, likely by lowering TG absorption and the inflammatory cytokine profile and attenuating gut dysbiosis.

\section{Lipase inhibitory activity of the components of PI}

ESI-Orbitrap-MS/MS was used to elucidate the components of the PI. A total of 15 compounds were identified (Additional file 1: Table S1); among them, six emerged as possible candidates based on published works: gallic acid, quinic acid, shikimic acid, $p$-hydroxybenzoic acid, protocatechuic acid, and malic acid [52-54]. Pure forms were procured and assayed for lipase inhibitory activity to validate the lipase inhibitory activity of the identified
Table 5 Specific lipase inhibition activities of compounds identified by MS/MS

\begin{tabular}{ll}
\hline Materials & Specific inhibition $^{\mathbf{a}}$ \\
\hline $\mathrm{PI}$ & $8.45 \pm 0.79$ \\
Flow-through from bonded-C18 & $5.14 \pm 0.42$ \\
Gallic acid & $0.73 \pm 0.019$ \\
4-Hydroxybenzoic acid & $0.43 \pm 0.018$ \\
Protocatechuic acid $_{\text {Mixture of all single compounds }}{ }^{\mathrm{b}}$ & $0.33 \pm 0.019$ \\
\hline
\end{tabular}

${ }^{a}$ The \%-inhibition values were divided by the masses $(\mu \mathrm{g})$ of the materials used in the assay $\pm S D$

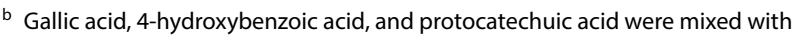
$17 \mu \mathrm{g}$ each

compounds. Among the six, gallic acid, 4-hydroxybenzoic acid, and protocatechuic acid showed significant lipase inhibitory activity (Table 5). However, the activity was not comparable (less than $10 \%$ ) to PI, even when all pure compounds were mixed (Table 5). Using bondedC18 to analyze the relative abundance of the compounds showed that the majority of the materials in PI were not bound or were loosely bound to the bonded-C18 column and eluted between 2 and $6 \mathrm{~min}$, and only gallic acid could be detected at very low concentrations (Additional file 1: Fig. S8A, B). The flow-through peaks were collected and assayed for lipase inhibitory activity against the pure compounds, and showed comparable (60.8\%) activity of PI (Table 5). This reconstitution assay suggests that PI should contain more potent lipase inhibitory molecule(s) than the molecules tested in this study.

Some studies have identified that the aggregation of polyphenolic compounds manifests nonspecific inhibitory activities on PLase [55]. In this study, PI was extracted from potatoes using deionized water, and then further purified by collecting flow-through fraction from reversed-phase chromatography. The components in PI also showed a short retention time from a reversed-phase column, inferring the absence of phenolic compounds such as flavonoids [56]. Given the high polarity, there is less likelihood of the components of PI to aggregate and present PLase inhibitory activity nonspecifically. Furthermore, the identified phenolic acids such as gallic acid showed significantly low relative abundance and could not completely reconstitute the lipase inhibitory activity of PI (Table 5).

Further studies on the compounds within PI using other ionization methods and high-resolution MS/MS techniques are mandatory to help further elucidate PI inhibition mechanisms. 


\section{Supplementary Information}

The online version contains supplementary material available at https://doi. org/10.1186/s13765-021-00590-w.

\begin{abstract}
Additional file 1: Fig. S1. Lipase inhibitory activities of $3 \mathrm{~mL} \mathrm{C18} \mathrm{column}$ fractions, gradient eluted with $1 \mathrm{~mL}$ of water mixed with increasing concentrations of methanol (MetOH), after injection of $1 \mathrm{~mL}$ of $1.144 \mathrm{~g} / \mathrm{mL}$ mix of butanol and ethyl acetate phase extract (ButOH/EA extract); 4-MUO used as a substrate. Each sample eluted with a percentage of methanol was evaporated then the volume adjusted back to $1 \mathrm{~mL}$ using deionised water. Fig. S2. Storage stability of Pl at different temperatures. Fig. S3. Substrate specificity. Fig. S4. Average food intake in the 4 mice groups (A); Normal diet (ND), high fat diet (HFD), high fat diet with Orlistat treatment (HFDOrl) and high fat diet with PI treatment (HFDPI). As a result of dominant mice aggression, there was reduced food intake between the 48th and 50th day especially in the HFDOrl group. (B) Fecal TG concentrations in the different groups represented as $\mathrm{mg} / \mathrm{dL}$ per milligram of fecal matter passed during a week \pm SE. Fig. S5. H\&E staining presents macrovesicular steatosis of the liver from the HFD group can be ameliorated by PI supplementation to HFD. Fig. S6. Effect of PI treatment (HFDPI) on a-diversity indices based on Chaol species richness index (A) and number of identified species observed (B) as compared to mice fed on Normal diet (ND), high fat diet (HFD) and high fat diet with Orlistat treatment (HFDOrlistat). Fig. S7. Microbial taxonomic profile of most abundant genus (grouped). Fig. S8. Chromatogram of Pl extract (A) and gallic acid (B) when analysed using reverse-phase HPLC-UV. Table S1. List of secondary metabolites of potato identified in negative ESI-MSMS.
\end{abstract}

\section{Abbreviations}

4-MUO: 4-Methylumbelliferyl oleate; CRP: C-reactive protein; DMSO: Dimethyl sulfoxide; HCl: Hydrochloric acid; HDL: High-density lipoprotein; HFD: Highfat diet; HPLC: High-performance liquid chromatography; $I C_{50}$ : Inhibitor concentration at 50\% substrate concentration; IL-6: Interleukin-6; IPGTT: Intraperitoneal Injection Glucose Tolerance Test; IPITT: Intraperitoneal Injection Insulin Tolerance Test; LDL: Low-density lipoprotein; ND: Normal diet; $p$-NPB: para-Nitrophenyl butyrate; TG: Triglycerides.

\section{Acknowledgements}

The authors are grateful to Dr. Jisun Oh from Dept. Food Biomaterials, KNU for her critical comments on the manuscript drafting. Dr. Kilsoo Kim from College of Veterinary Medicine, $\mathrm{KNU}$, is acknowledged for helpful advice on the animal experiments.

\section{Authors' contributions}

Animal experiment: DAK, JL. Conceptualization: JL, CKK, DH. Funding acquisition: JL. Investigation: DAK, JM. Method development: DAK, JM, DH. Supervision: JL. Writing and review and editing: DAK, JL. All authors have agreed to the published version of the manuscript. All authors read and approved the final manuscript.

\section{Funding}

This research was funded by a research grant from Korea National Research Foundation (NRF-2017R1D1A1B04035876).

\section{Competing interests}

The authors declare that they have no competing interests.

\section{Author details}

${ }^{1}$ Department of Food Biomaterials, Kyungpook National University, 80 Daehak-Ro, Buk-Gu, Daegu, Korea. ${ }^{2}$ Department of Horticulture Science, Kyungpook National University, Daegu, Korea.

Received: 29 November 2020 Accepted: 11 January 2021 Published online: 09 February 2021

\section{References}

1. WHO (2018) Obesity and overweight. Fact sheet. 311. https://www.who. int/news-room/fact-sheets/detail/obesity-and-overweight

2. Xie M, Chen G, Wan P, Dai Z, Zeng X, Sun Y (2019) Effects of dicaffeoylquinic acids from Ilex kudingcha on lipid metabolism and intestinal microbiota in high-fat-diet-fed mice. J Agric Food Chem 67:171-183

3. Ley RE, Turnbaugh PJ, Klein S, Gordon JI (2006) Human gut microbes associated with obesity. Nature 444:1022-1023

4. Turnbaugh PJ, Ley RE, Mahowald MA, Magrini V, Mardis ER, Gordon JI (2006) An obesity-associated gut microbiome with increased capacity for energy harvest. Nature 444:1027-1031

5. Mandic AD, Blaut M (2018) Do we choose control diets wisely? Trends Endrocrinol Metabol 29:7

6. Liao W, Yin X, Li Q, Zhang H, Liu Z, Zheng X, Zheng L, Feng X (2018) Resveratrol-induced white adipose tissue browning in obese mice by remodeling fecal microbiota. Molecules 23:3356

7. Kumar P, Dubey KK (2015) Current trends and future prospects of lipstatin: a lipase inhibitor and pro-drug for obesity. R Soc Chem 5:86954-86966

8. Chanmee W, Chaicharoenpong C, Petsom A (2013) Lipase inhibitor from fruits of Solanum stramonifolium Jacq. Food Nutr Sci 4:554-558

9. Subandi LZ, Brotosudarmo THP (2019) Saponin from purple eggplant (Solanum melongena L.) and their activity. IOP Conf Ser Mater Sci Eng 509:012139

10. Franson K, Rössner S (2000) Fat intake and food choices during weight reduction with diet, behavioural modification and alipase inhibitor. J Intern Med 247:607-614

11. O'Donovan D, Horowitz M, Russo A, Feinle-Bisset C, Murolo N, Gentilcore D, Wishart JM, Morris HA, Jones KL (2004) Effects of lipase inhibition on gastric emptying of, and on the glyceamic, insulin and cardiovascular responses to, a high-fat/carbohydrate meal in type 2 diabetes. Diabetologia 47:2208-2214

12. Barta J, Bártová V, Zdrahal Z, Sedo O (2012) Cultivar variability of patatin biochemical characteristics: table versus processing potatoes (Solanum tuberosum L.). J Agric Chem 60:4369-4378

13. James A, Strickland CO, Terence A (1995) Inhibition of Diabrofica larval growth by patatin, the lipid acyl hydrolase from potato tubers. Plant Physiol 109:667-674

14. Bollag DM, Edelstein SJ (1996) Protein methods. Wiley-Liss, New York

15. Pots AM, de Jongh HHJ, Gruppen H, Hamer RJ, Voragen AGJ (1998) Heat induced conformational changes of patatin, the major potato tuber protein. Eur J Biochem 252:66-72

16. Vorderwulbecke T, Kieslich K, Erdmann H (1992) Comparison of lipase by lipases by different assays. Enzyme Microb Technol 14:631-639

17. Nakai M, Fukui Y, Asami S, Toyoda-Ono Y, Iwashita T, Shibata H, Mitsunaga T, Hashimoto F, Kiso Y (2005) Inhibitory effects of Ooling tea polyphenols on pancretic lipase in vitro. J Agric Food Chem 53:4593-4598

18. Admassu H, Gasmalla MAA, Yang R, Zhao W (2018) Identification of bioactive peptides with a-amylase inhibitory potential from enzymatic protein hydrolysates of red seaweed (Porphyra spp.). J Agric Food Chem 66:4872-4882

19. Moreno-Córdovaa EN, Arvizu-Flores AA, Valenzuela-Soto EM, GarcíaOrozco KD, Wall-Medrano A, Alvarez-Parrilla E, Ayala-Zavala JF, Domínguez-Avila JA, González-Aguilar GA (2020) Gallotannins are uncompetitive inhibitors of pancreatic lipase activity. Biophys Chem 264:106409

20. Jo YH, Kim SB, Liu Q, Do SG, Hwang BY, Lee MK (2017) Comparison of pancreatic lipase inhibitory isoflavanoids from unripe and ripe fruits of Cudrania tricuspidata. PLOS ONE 12:e01720169

21. Lee S, Cho Y, Kim S (2014) Development and application of a software tool for the interpretation of organic mixtures'spectra-hydrogen deuterium exchange (STORM-HDX) to interpret APPI HDX MS spectra. Bull Korean Chem Soc 35:749-752

22. Tamer F, Ulug E, Akyol A, Nergiz-Unal R (2019) The potential efficacy of dietary fatty acids and fructose induced inflammation and oxidative stress on the insulin signalling and fat accumulation in mice. Food Chem Toxicol 135:110914 
23. Rideout JR, He Y, Navas-Molina JA, Walters WA, Ursell LK, Gibbons SM, Chase J, McDonald D, Gonzalez A, Robbins-Pianka A, Clemente JC, Gilbert JA, Huse SM, Zhou HW, Knight R, Caporaso JG (2014) Subsampled openreference clustering creates consistent, comprehensive OTU definitions and scales to billions of sequences. Peer J 2:e545

24. Yarza P, Yilmaz P, Pruesse E, Glöckner FO, Ludwig W, Schleifer KH, Whitman WB, Euzeby J, Amann R, Rosselló-Móra R (2014) Uniting the classification of cultured and uncultured bacteria and archaea using 165 rRNA gene sequences. Nat Rev Microbiol 12:635-645

25. Fiorini D, Boarelli MC, Gabbianelli R, Ballini R, Pacetti D (2016) A quantitative headspace-solid-phase microextraction-gas chromatography-flame ionization detector method to analyze short chain free fatty acids in rat feces. Anal Biochem 508:12-14

26. Patil SG, Patil MP, Maheshwari VL, Patil RH (2015) In vitro lipase inhibitory effect and kinetic properties of di-terpenoid fraction from Calotropis procera (Aiton). Biocatal Agric 4:579-585

27. Alejandra I, Martinez-Gonzalez Al, Alvarez-Parrilla E, Díaz-Sánchez AG, de la Rosa L, Núñez-Gastélum JA, Vazquez-Flores AA, Gonzalez-Aguilar GA (2017) In vitro inhibition of pancreatic lipase by polyphenols: a kinetic, fluorescence spectroscopy and molecular docking study. Food Technol Biotechnol 55:519-530

28. Hackl MT, Fürnsinn C, Schuh CM, Krssak M, Carli F, Guerra S, Freudenthaler A, Baumgartner-Parzer S, Luger A, Zeyda M, Gastaldelli A, Buettner C, Scherer T (2019) Brain leptin reduces liver lipids by increasing hepatic triglyceride secretion and lowering lipogenesis. Nat Comm 10:2717

29. Hammad MM, Abu-Farha M, Al-Taiar A, Alam-Eldin N, Al-Sabah R, Shaban L, Al-Mulla F, Abubaker J, Rahman A (2020) Correlation of circulating ANGPTL5 levels with obesity, high sensitivity C-reactive protein and oxidized low-density lipoprotein in adolescents. Sci Rep 10:6330

30. Torres S, Fabersani E, Marquez A, Guaffin-Cano P (2018) Adipose tissue inflammation and metabolic syndrome. Eur J Nutr 58:27-43

31. Park HS, Park JY, Yu R (2005) Relationship of obesity and visceral adiposity with serum concentrations of CRP, TNF- $a$ and IL-6. Diabetes Res Clin 69:29-35

32. Park HS, Park JY, Yu R (2005) Relationship of obesity and visceral adiposity with serum concentrations of CRP, TNF-a and IL-6. Diabetes Res Clin Pract 69:29-35

33. Blüher M, Fasshauer M, Tönjes A, Kratzsch J, Schön MR, Paschke R (2005) Association of interleukin-6, C-reactive protein, interleukin-10 and adiponectin plasma concentrations with measures of obesity, insulin sensitivity and glucose metabolism. Exp Clin Endocrinol Diabetes 113:534-537. https://doi.org/10.1055/s-2005-872851

34. Hung TV, Suzuki T (2018) Short-chain fatty acids suppress inflammatory reactions in Caco-2 cells and mouse colons. J Agric Food Chem 66:108-117

35. Vinolo MAR, Rodrigues HG, Nachbar RT, Curi R (2011) Regulation of inflammation by short chain fatty acids. Nutrients 3:858-876

36. Pérez-Matute $P$, Íñiguez M, de Toro M, Recio-Fernández M, Oteo JA (2020) Autologous fecal transplantation from a lean state potentiates caloric restriction effects on body weight and adiposity in obese mice. Sci Rep 10:9388

37. Kanauchi O, Andoh A, Mitsuyama K (2013) Effects of the modulation of microbiota on the gastrointestinal immune system and bowel function. J Agric Food Chem 61:9977-9983

38. Mujico JR, Bacca GC, Gheorghe A, Diaz LE, Marcos A (2013) Changes in gut microbiota due to supplemented fatty acids in diet-induced obese mice. Br J Nutr 110:711-720

39. Terzo S, Mule F, Coldaro GF, Baldassano S, Puleio R, Vitale M, Cassata G, Ferrantelli V, Amato A (2020) Pistachio consumption alleviates inflammation and improves gut microbiota composition in mice fed a high-fat diet. Inter J Mol Sci 21:365

40. Qu L, Liu Q, Zhang Q, Tuo X, Fan D, Deng J, Yang H (2019) Kiwifruit seed oil prevents obesity by regulating inflammation, thermogenesis, and gut microbiota in high-fat diet-induced obese C57BL/6 mice. Food Chem Toxicol 125:85-94
41. Méndez-Salazar EO, Ortiz-López MG, Granados-Silvestre MDLÁ, PalaciosGonzález B, Menjivar M (2018) Altered gut microbiota and compositional changes in Firmicutes and Proteobacteria in mexican undernourished and obese children. Front Microbiol. https://doi.org/10.3389/fmicb .2018 .02494

42. Ke J, An Y, Cao B, Lang J, Wu N, Zhao D (2020) Orlistat-induced gut microbiota modification in obese mice. Evid Based Complementary Altern Med 2020:9818349

43. Schroll JB, Penninga El, Gøtzsche PC (2016) Assessment of adverse events in protocols, clinical study reports, and published papers of trials of orlistat: a document analysis. PLoS Med 13:e1002101. https://doi. org/10.1371/journal.pmed.1002101

44. Kang Z, Lu M, Jiang M, Zhou D, Huang H (2019) Proteobacteria acts as a pathogenic risk-factor for chronic abdominal pain and diarrhea in postcholecystectomy syndrome patients: a gut microbiome metabolomics study. Med Sci Monit 25:7312-7320

45. Mahnic A, Breskvar M, Dzeroski S, Skok P, Pintar S, Rupnik M (2020) Distinct types of gut microbiota dysbiosis in hospitalized gastroenterological patients are disease non-related and characterized with the predominance of either enterobacteriaceae or enterococcus. Front Microbiol $11: 120$

46. Han F, Wang Y, Han Y, Zhao J, Han F, Song G, Jiang P, Miao H (2018) Effects of whole-grain rice and wheat on composition of gut microbiota and short-chain fatty acids in rats. J Agric Food Chem 66:6326-6335

47. Elamin EE, Masclee AA, Dekker J, Pieters HJ, Jonkers DM (2013) Shortchain fatty acids activate AMP-activated protein kinase and ameliorate ethanol-induced intestinal barrier dysfunction in Caco-2 cell monolayers. J Nutr 143:1872-1881

48. McNabney SM, Henagan TM (2017) Short chain fatty acids in the colon and peripheral tissues: a focus on butyrate, colon cancer, obesity and insulin resistance. Nutrients 9:1348

49. Knudsen KEB, Lærke HN, Hedemann MS, Nielsen TS, Ingerslev AK, Nielsen DSG, Theil PK, Purup S, Hald S, Schioldan AG, Marco ML, Gregersen S, Hermansen K (2018) Impact of diet-modulated butyrate production on intestinal barrier function and inflammation. Nutrients 10:1499

50. Du H, Zhao A, Wang Q, Yang X, Ren D (2020) Supplementation of inulin with various degree of polymerization ameliorates liver injury and gut microbiota dysbiosis in high fat-fed obese mice. J Agric Food Chem 68:779-787

51. Havlik J, Marinello V, Gardyne A, Hou M, Mullen W, Morrison DJ, Preston T, Combet E, Edwards CA (2020) Dietary fibres differentially impact on the production of phenolic acids from rutin in an in vitro fermentation model of the human gut microbiota. Nutrients 12:1557

52. Oi Y, Hou I-C, Fujita H, Yazawa K (2012) Antiobesity effects of Chinese Black Tea (Pu-erh Tea) extract and gallic acid. Phytother Res 26:475-481

53. Zhang B, Deng Z, Ramdath DD, Tang Y, Chen PX, Liu R, Liu Q, Tsao R (2015) Phenolic profiles of 20 Canadian lentil cultivars and their contribution to antioxidant activity and inhibitory effects on alpha-glucosidase and pancreatic lipase. Food Chem 172:862-872

54. Alakolanga AGAW, Kumar NS, Jayasinghe L, Fujimoto Y (2015) Antioxidant property and a-glucosidase, a-amylase and lipase inhibiting activities of Flacourtia inermis fruits: characterization of malic acid as an inhibitor of the enzymes. J Food Sci Technol 52:8383-8388

55. Bustos ASHA, Linares-Pastén JA, Peñarrieta JM, Nilsson L (2020) Interaction of quercetin and epigallocatechin gallate (EGCG) aggregates with pancreatic lipase under simplified intestinal conditions. PLOS ONE. https ://doi.org/10.1371/journal.pone.0224853

56. Crozier A, Jensen E, Lean MEJ, McDonald MS (1997) Quantitative analysis of flavonoids by reversed-phase high-performance liquid chromatography. J Chromatogr A 761:315-321

\section{Publisher's Note}

Springer Nature remains neutral with regard to jurisdictional claims in published maps and institutional affiliations. 